\title{
Emerging Trends in ICTs and its impact on Organizational Innovation through Knowledge Management
}

\author{
Arifusalam Shaikh ${ }^{l}$, Abul Bashar ${ }^{2}$ and Muhammad Rafiq ${ }^{l}$ \\ ${ }^{1}$ College of Business Administration, Prince Mohammad bin Fahd University, Al-Khobar, \\ Saudi Arabia \\ ${ }^{2}$ College of Computer Engineering and Science, Prince Mohammad bin Fahd University, Al- \\ Khobar, Saudi Arabia \\ Corresponding Author: Muhammad Rafiq
}

\begin{abstract}
Organizations have benefited immensely since the evolution of Knowledge Management (KM). While KM found its place among the business activities, it has been greatly acknowledged that it has created significant opportunities for innovation. Several articles are found in literature that discusses the role of KM in innovation. Most of the articles discuss how Information and Computer Technology (ICT) has been the driver of such contributions through KM. However, there are very few articles that present the innovation trends within the KM domain. The role of ICT is not limited to organizational innovation and has demonstrated its impact on innovation within KM. This article is an effort to present emerging trends focusing on organizational innovation through KM. Some of the prominent ones which will be dealt in detail are the utilization of social networks, incorporation of RFID solutions and the adaptation of cloud computing in KM.
\end{abstract}

Key words: Innovation, Knowledge Management, Information Technology, Information and Computer Technology (ICT), ICTs Trends

\section{INTRODUCTION}

Organizations now consider Knowledge Management $(\mathrm{KM})$ as a building block for their growth and competency. It is stated that $\mathrm{KM}$ is a vital resource, in an individual or in an organization [1]. The fundamental definition of KM consists of information related components like capturing/creating, storing, disseminating, analyzing, aiding innovation, etc. Given the variety of processes involved, it is a challenging task to manage knowledge in an organization which directly adds value to the competitive advantage of the organization. This complexity of managing knowledge has been the key factor for several organizations to take steps to develop knowledge management systems (KMS). A good summary of knowledge definitions and their implications with regard to KM and KMS is provided in [2]. The very nature of $\mathrm{KM}$ demonstrates its dependency on Information and Communications Technology (ICT) and therefore the trends in KM are correlated to the trends in ICTs. ICT has been the driver of KM and any innovation in ICTs were easily adapted in KM. Figure 1 demonstrates the adoption and impact 


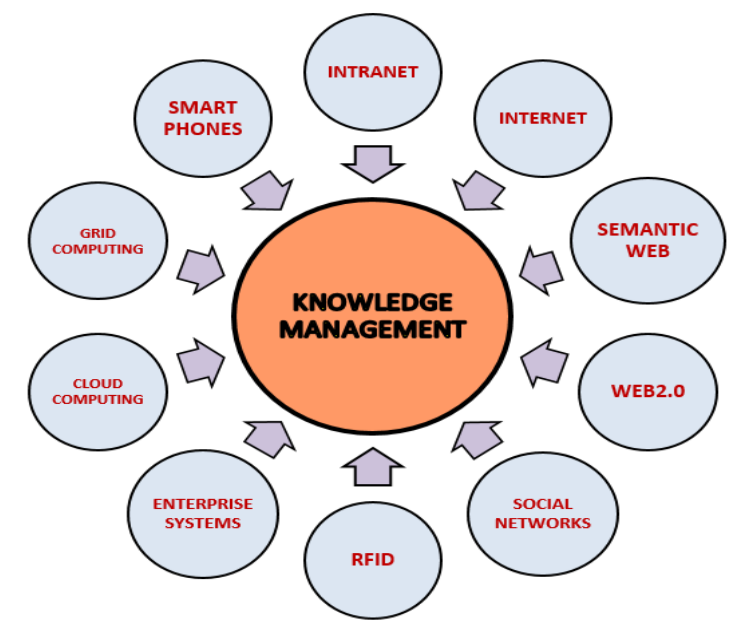

Figure 1: Impact and Adoption of ICTs in Knowledge Management

of various prominent ICTs in KM. While it is easy to identify the importance of ICT in KM, it is indeed a difficult task to implement KMS in organizations. The issues of implementing KMS are addressed and discussed in literature to enhance the effectiveness and efficiency of implementing KMS through appropriate ICT [3]. Once the KMS is setup, it provides immense benefits to the organization and among many other benefits is its support to Organizational Innovation (OI). Availability of knowledge in its best form for the right users at the right time is the necessity of OI. While efficient KM enhances the rate of innovation, it must be acknowledged that the designers of KMS have to find innovative ways of building KMS. They must keep themselves updated to what ICTs have to offer and evaluate its utilization for KM. While the technicalities play important role in adoption, several other issues including cost effectiveness and features enhancing competitive advantage of the organization also play a crucial role. The focus of this paper is to discuss the role of $\mathrm{KM}$ in $\mathrm{OI}$ and to present recent trends in ICT contributing to OI.

The rest of the paper is organized as follows. In section 2, a detailed study of innovation and its relationship with $\mathrm{KM}$, the importance of ICT and its link with OI will be discussed. In section 3 recent trends of ICTs will be presented that are impacting the way KMS are developed. A scenario demonstrating the use of current ICTs to acquire and disseminate information and knowledge will be presented in section 4 and conclusions in section 5 .

\section{INNOVATION AND KM}

Ever since humanity originated, innovation also existed, as people always looked for new and better ways of lifestyle and convenience. In business, innovation has become a necessity and if ignored, would risk losing competitive advantage and eventually the market. As businesses grew and expanded over horizons it became challenging not only to manage their knowledge, but also to enhance their competitive advantage in an innovative way. One of the pioneering works by Nonaka [4] discusses about the importance of creating knowledge and the significance of becoming a "Knowledge-creating" company [4]. He strongly believed that knowledge creation is the key for continuous innovation. He further clarified that knowledge transforms from tacit to tacit, explicit to explicit, tacit to explicit, and explicit to tacit forms. The last two forms of transformation are very vital to OI. In the following subsections, we will first discuss innovation by presenting various aspects addressed by researchers over time and then the link between KM and OI. The emerging trends in OI within knowledge management will be discussed in section 3.

2.1 Organizational Innovation: Innovation is taken from Latin words nova and innovare, which means designing something new or making something new. Thus, creating new entity and bringing it to its final market form is known as innovation [5]. Innovation is a new product or service in the market with new features or any old entity commercialized in such a way to open new uses. The realization of new products, services, process, technology or simply doing something in new way is known as innovation [6]. It is mentioned that although innovation is not a new phenomenon, it is mandatory to the economy and competitive advantage of any organization [7]. It is argued that innovation must be managed to provide an atmosphere and meet all necessary conditions to generate new knowledge and to transform it to a tangible forms like new product, technology or process among others [8]. As services are intangible in nature, therefore, innovation in services is different than innovation in products. Exchange of services is just a negotiated exchange between customer and supplier while exchange of product is 
the physical exchange of product and both of them are essential to the economy [9].

OI has been defined by many researchers in different ways, and all reflect business challenges in their era. It is observed that most of the definitions include terms like, new products, new services, creativity, improvement, new systems or processes that are among the prominent ones. It is also seen that many of them directly reflect knowledge management activities. It is understandable that innovation is not possible without seeking knowledge of products, processes, ideas, systems and technologies. It is therefore necessary to study the link between knowledge management and OI in detail and understand how researchers have addressed this issue.

2.2 The link between $\mathrm{KM}$ and OI: Every organization has a knowledge domain that encompasses knowledge of its elements in the internal environment as well as several related aspects of the external environment. How this knowledge from internal and external environment influences innovation depends on how efficiently the knowledge is managed at this organization. One of the works by [10] presents three drivers for application of knowledge management in innovation. The first one for innovation in today's business environment is to create, build and maintain competitive advantage through utilization of knowledge and through collaboration practices. The second is the acknowledgement of knowledge as a resource that can be used to reduce complexity in innovation process. The last one is to benefit the innovation process through integration of knowledge both internal and external to organization.

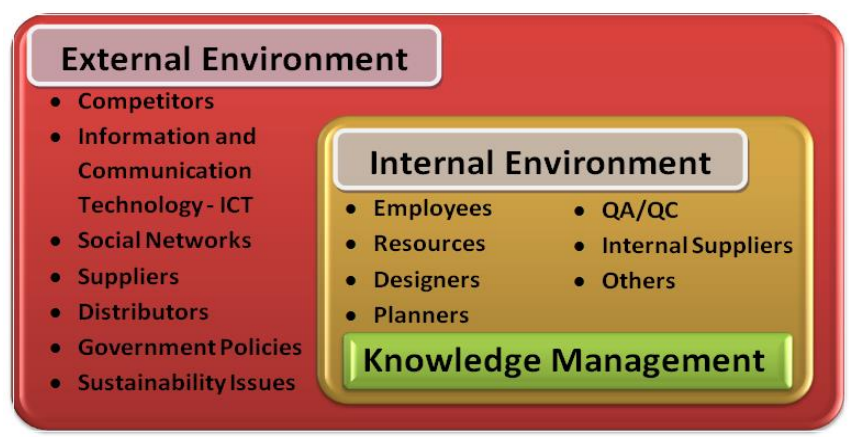

Figure 2: The key elements of the internal and external environment

Figure 2 provides the elements belonging to the internal environment and the external environment of an organization. The key elements of the internal environment are employees, resources, designers, planners, etc., whose roles and responsibilities have a direct impact on innovation. The elements of external environment also have direct impact on innovation. Many known innovations in this world are a result of ideas developed initially from competitors. Developments in the ICTs is an undeniable factor for the growth in innovation.

The emergence of social networks has opened a new avenue for innovations since the customers are playing a bigger role as sources of innovation. The ideas from suppliers and distributors have always been important for business coordination and had been a source for new ideas. Government policies do play a vital role in innovation, for example if the government launches a policy to cut down the use of fossil fuels, innovators actively worked on developing alternative fuels. Sustainability issues can also lead to innovations, like Walmart recognized the need of going green and this forced the innovation of a variety of green packing material.
Eight KM activities are listed in [11] namely, knowledge creation, acquisition, capturing, assembling, sharing, integration, leverage and exploitation The author broadly categorized these activities into three dynamic capabilities such as knowledge development, knowledge (re)combination and knowledge use. A study explored the relationship between knowledge management practices and innovation performance and presented the concept of incremental and radical innovation [12]. According to the authors, incremental innovations present themselves as line extensions or modifications of existing products, while radical innovations are likely to be competence-destroying, often making existing skills and knowledge redundant and necessitating different management practices.

A survey was conducted related to innovation which concluded that knowledge acquisition and responsiveness to knowledge are more important for innovation than knowledge dissemination [13]. In knowledge practices, the focus is on connecting people and thus may involve company experts, communities of practice, and enhancing and 
enabling networks through shared social activities [14]. It is stated that innovation process includes knowledge, its management and human capital that is essential for any type of business [12].

A study was conducted which consisted of 310 Spanish organizations and structural equations modeling to study the impact of two KM strategies (codification and personalization) on innovation [15]. They concluded that KM is an important mechanism for companies to be more innovative, efficient and effective. It was proposed to have an integrated approach of KM to foster innovation in design [16]. The basis of their model is a systemic model of knowledge and a hierarchical model composed by the macro process and meta-model of KM. Their model provides an effective means of integrating different perspectives of $\mathrm{KM}$ and its activities that can enable designers to innovate more easily and efficiently. A good literature survey on $\mathrm{KM}$ and Innovation that examines the relationship between their processes is presented in [17].

The issue of developing and implementing an effective system of knowledge management in the modern enterprises for innovativeness was also proposed [18]. They emphasized that knowledge management affects better utilization of enterprises' resources for creating innovations and increasing their absorptive capacity. They presented the most important roles that knowledge management plays in improving innovation capability of an enterprise, which are codifying and sharing tacit knowledge, acquiring and sharing explicit knowledge, enabling cooperation within and outside the enterprise, knowledge integration, knowledge availability, and creating organizational culture based on knowledge and innovation.

An excellent example that demonstrates the link between KM and innovation is health care industry where it is a necessity to have an excellent KMS coupled with innovation that sustains a competitive edge. A conceptual model to test the moderating effect of cultural barriers that links knowledge strategies and innovation using healthcare organizations was proposed [19]. They concluded that organizations that have low barriers to knowledge creativity and sharing, facilitate knowledge transfer, promote open cultures, and have a strong knowledge-innovation link.

Another study examines the effect of knowledge management on innovation directly and through Organizational Learning (OL) [20]. They concluded that senior experienced organization members in KM can enhance the performance of the organization through commitment to learning, shared vision and open-mindedness.

\section{ICTS TRENDS SUPPORTING OI THROUGH KM}

There is no ambiguity in accepting that the OI has a direct relationship with KM. It is also acknowledged that the way KM activities are conducted like creating, storing, disseminating, etc are all in its state of art because of the exponential growth in the ICTs. It is out of scope for this paper to address all technologies that have direct influence on KM activities and therefore the three most significant developments are addressed. The first one is the advent of the concept of social networking, second is the emergence of Radio Frequency Identification (RFID) and its impact on business processes and the last one is Cloud Computing (CC).

3.1 Social Networks and KM: The use of social networks has become one of the basic necessities of people. The number of users is so high that it cannot be ignored by organizations and in fact they utilize the opportunity and build strategies to actually market their products, enhance customer relations, gain knowledge of customers, their likes/dislikes, business analytics, etc. The amount of information available in these social networking sites is so huge that it is challenging to get full advantage of it. Several analytical tools are hence developed to extract useful information for business and use it for promoting their products and services as well as enhancing KM within the organization.

A study was conducted to determine means of improving employees' ability to create and share knowledge in important social networks [21]. They surveyed managers to identify the people most important to them in terms of information or knowledge acquired for that project and had them carefully describe relationships. Formal structure of the considered organization was compared with the informal structures resulted through social networks. The results can be used to develop mitigating measures that could minimize dependency on a a specific resource and facilitate efficient knowledge management. It was emphasized that addressing feedback is an important element of the organizational learning and aids in creating knowledge [22]. He further stated that social networks also form a resource for collaborative knowledge management and may aid the process of organizational learning.

While extracting information, storing and reaching out to customers is also considered among the KM activities, what has become more important in view of innovation is the opportunity to get new ideas from the customers and reviewers who are actively participating on these social networks. Consumers assume different roles from announcer or discloser 
even up to criticizer of a company while participating in social networks [23]. The consumers may sometimes actually suggest new products, therefore providing ideas for potential innovations, and may even act as disclosers of new products and services [24].

One of the studies provided three recommendations for organizations planning to implement social networking systems for knowledge management [25]. They recommended organizations to balance privacy and flexibility, structure socially driven KM, and enable continued leadership. A study separated social networks into internal and external social networks acknowledging the existence of an organizational boundary among members [26]. They examined the influence of social networks on knowledge management in public sector organizations. Through regression analysis results they inferred that external social network is positively associated with knowledge sharing and internal social network is positively associated with high level of knowledge acquisition.

3.2 RFID and KM: RFID is a wireless technology that can transmit information through radio waves. It does not need any physical connection or line of sight communication, like bar codes. An RFID tag, also called as transponder has a microchip that can store data and can identify the item it is attached to, and an antenna that transmits the data. The RFIDs are available in three types passive, active and semipassive or semi-active. The reader sends radio signals and prompts the tag to broadcast the data stored in the chip, and then the reader starts converting the radio waves that are returned from the tags to digital data and sends them to a computer system [27][28].

Sundaram et al [29] proposed a knowledge-based Web Service architecture through a working prototype based on the idiosyncrasies of RFID applications. This application can sustain a more coherent and productive service than traditional integrated systems for supply chain management. The use of RFID in supply chain macro process is well described in [30]. Not surprisingly, RFID is now adapted to facilitate $\mathrm{KM}$ activities in various industries. In the following some sample cases of RFID applications related to KM will be presented.

Another study [31] presented a RFID based knowledge management systems (RFID-KMS) with real-time knowledge support. They developed a decision support system to solve this problem and it helped in increasing productivity as well as creating an organizational learning atmosphere. Their pilot project also showed enhancements in operation levels, resource management improvement and continuous improvement.
Ahsan et al [32] presented a detailed review of RFID and its applications. The concept of contextbased knowledge management was put forward, that would use mobile technology implementation within patients' movement processes. A generic model of Knowledge asset capturing in healthcare industry was also presented by Ahsan et al [33] that utilized mobile technology. For an existing heath care solution model, they hooked RFID Technology that delivered continuous knowledge growth and management without affecting the existing systems. Ghazali et al [34] discussed the potential of RFID as an enabler of knowledge management and collaboration for the procurement cycle in the construction industry.

3.3 Cloud Computing and KM: Cloud computing is another trend in ICT that has made an impact on how businesses operate. Cloud Computing is typically defined as a computing model where there is a concept of sharing IT resources as opposed to setting up local IT resources for meeting the computing needs of an organization. It is an Internetbased computing where the various IT services like computing power, storage and networking are delivered to meet the organization's additional requirements of computing facilities.

The reason for widespread deployment and acceptability of the Cloud Computing model is due to the various benefits it offers over the traditional IT setup. Firstly, it is the financial benefit, which is because now the organization can reduce its IT setup and maintenance costs by subscribing to the IT services rather than purchasing the IT resources. Secondly, it brings in the ease of management of IT needs from the organization's perspective since the hardware and software maintenance is now the responsibility of the Cloud Computing service provider. Thirdly, the advantage of the on-demand service provisioning is achieved since the service provider can scale up or scale down IT resources based on the client demands. Finally, there is the notion of unlimited IT resources (CPU, Memory, Storage and Bandwidth) as they are pooled at one place and can be dynamically made available when required.

Knowledge Management Systems (KMS) can benefit from the Cloud Computing technology by incorporating the rich features and benefits mentioned as above. In fact, there is a significant research which proves that KMS are harnessing the 
benefits of Cloud Computing. KMS have been positively affected by this disruptive technology by getting an ability to create new business models for the organization and make them equipped with the latest technology to compete and thrive in the business market. Sultan et al [35] observed that with the application of Cloud Computing to the KMS a new era of knowledge-rich systems can be developed for those organizations who have limited means and resources. In another work, Abdullah et al [36] propose a model which combines the Knowledge Management System and Cloud Computing concepts to provide Knowledge as a Service (KaaS).

Lin et al [37] proposed a new architecture for a Customer Knowledge Management Information System (CKMIS) which utilizes the features of Software as a Service (SaaS) from the Cloud Computing setup. Another application of Cloud Computing model to the KMS is in the higher education sector. A recent work by Bimol et al [38] propose to implement the KMS of a higher education establishment by use of cost-effective and viable Cloud Computing setup.

\section{PROPOSED SCENARIO}

Since it is out of scope of this paper to cover all KM activities of an organization, we present a hypothetical maintenance and customer support department of an appliance manufacturing company. Let's assume that a major appliance manufacturing company distributes its products to several retail outlets globally. When the products are purchased at a location, a geographical area is allocated to one of its closest service centers where they cater to product returns and serve warranty issues that may need replacement or repair of defective items. Since every organization is striving to provide best services to its customers, they look forward to adopt intelligent systems that can improve their performance and increase efficiency. These intelligent systems utilize the concept of IoT (Internet of Things) where information can be made available to all concerned departments and employees on-site and off-site by connecting devices through wired and/or wireless networks. This provides the platform for information mobility which simultaneously opens options for enhanced knowledge management, where the required information/content can be accessed/dissipated ubiquitously.

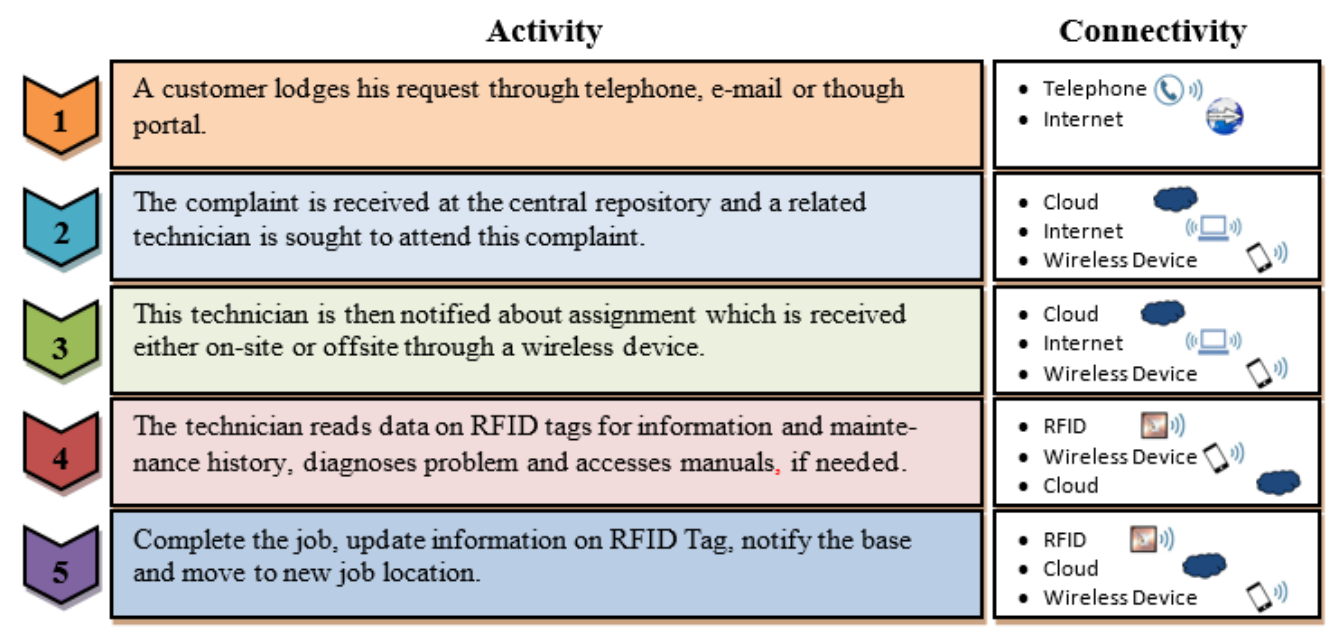

Figure 3: Maintenance department activities and related connectivity types

In the current scenario, customers who face issues in operating the appliance or need to complain about the defective product have to call the toll free number or can lodge their complaints online through the portal. The complaint is received at the central repository and a related technician is sought to attend this complaint. With the aid of intelligent systems, a technician is identified, and his availability is determined. This technician is then notified about his next assignment which he receives either on-site or offsite through a wireless device and confirms acceptance of job which is updated on his assignments schedule. The information he receives will include the details of the customer, nature of job and the location details. The technician may utilize GPS solutions to reach the location efficiently. On his visit to the customer's location, he will use his expertise to identify the problem and fix it. These appliances may be equipped with RFID tags that give the history of maintenance that may aid the 
technician to diagnose the problem quickly. If the technician has experience in the problem, he may immediately fix it, else he may seek online help to obtain the manual/video that may provide him with a step-wise procedure to solve the problem. He may access this through cloud using his wireless device. Figure 3 shows the type of connectivity and devices used in the whole process to demonstrate the scenario mentioned above.

\section{CONCLUSIONS}

Emerging trends in ICTs were discussed that lead to OI through KM. The study focused on utilization of social networks, RFID solutions and cloud computing in developing KMS which have now paved way to smart KMS. A scenario was then presented that demonstrated the combination of technologies that can be utilized to manage knowledge efficiently and in a real time scenario. The exponential growth in ICTs has and will always play a major role in the development of smart KMS. The current era demands a real time dynamic knowledge sharing facility that can aid OI and concurrent decision making Since ICT by nature will keep evolving and provide the world with amazing solutions it is observed that organizations now seek intellectuals who are more creative in utilizing the available technologies. The potential in utilizing state of the art ICTs is so huge that it demands creativity among designers to develop smart KMS.

\section{REFERENCES}

[1] Jelenic, D. (2011), "The Importance of Knowledge Management in Organizations: With Emphasis On The Balanced Scorecard Learning and Growth Perspective", Paper presented at Management, Knowledge and Learning International Conference, Celje, Slovenia, pp.33-43. [2] Alavi, M. and Leidner, D. E. (2001), "Knowledge Management and Knowledge Management Systems: Conceptual Foundations and Research Issues", $\hat{\imath}$ MIS Quarterly, Vol.25, No.1 pp.107-136.

[3] Tseng, S. M. (2008), "Knowledge management system performance measure index", Expert Systems with Applications, Vol.34 No. 1 pp.734745.

[4] Nonaka, I. (1991), "The knowledge-creating company" Harvard business review, Vol.69 No. 6 pp.96-104.

[5] Tidd, J., Bessant, J. and Pavitt, K. (2001), "Managing innovation:Integrating technological,
Market and Orginizational change",UK, John Wiley and Sons.

[6] Westland, C. (2008), "Global innovation management", A strategic approach, New York.

[7] Porter, M. (1990), "The competitive advantage of nations", London, McMillan

[8] Bratianu, C. (2011), "Management \& Marketing Challenges for the Knowledge Society", Vol.6 No.4 pp.515-528.

[9] Uden, L. and Naaranoja, M. (2009), "Service Innovation by SME", International Journal of Web Engineering and Technology, Vol.5 No.3 pp.268294.

[10] Plessis, M.D. (2007), "The Role of Knowledge Management in Innovation", Journal of Knowledge Management, Vol.11 No.4 pp.20-29.

[11] Nielson, A.P. (2006), "Understanding dynamic capabilities through knowledge management", Journal of Knowledge Management, Vol. 10 No. 4 pp.59-71.

[12] Gloet, M. and Terziovski, M. (2004), "Exploring the relationship between knowledge management practices and innovation performance", Journal of Manufacturing Technology Management, Vol. 15 No.5 pp. 402409.

[14] Matthews, J. H. (2003), “Knowledge Management and Innovation: How are they related"? In Timbrell, Greg, Eds. Proceedings KM Challenge 2003 Knowledge Management Conference, Melbourne Australia.

[15] Lopez-Nicolas, C. and Merono-Cerdan, A. L. (2011), "Strategic knowledge management", innovation and performance. International Journal of Information Management, Vol.31 pp.502-509.

[16] Xu, J., Houssin, R., Caillaud, E. and Gardoni, M. (2011), "Fostering continuous innovation in design with an integrated knowledge management approach", Computers in Industry,Vol. 62 No. 4 pp.423-436.

[17] Akram, K., Siddiqui, S.H., Nawaz, M.A.,Ghauri, T.A. and Cheema, A.K.C.( 2011), "Role of Knowledge Management to Bring Innovation: An Integrated Approach", International Bulletin of Business Administration, Vol.11 pp.121134.

[18] Krstić, B. and Petrović, B. (2012), "The role of knowledge management in increasing entrerprise's innovativeness", Facta Universitatis, Series:

Economics and Organization, Vol. 9 No. 1 pp. 93 110. 
[19] Leal-Rodríguez, A., Leal-Millán, A., RoldánSalgueiro, J. L. and Ortega- Gutiérrez, J. (2013), "Knowledge Management and the Effectiveness of Innovation Outcomes: The Role of Cultural Barriers", The Electronic Journal of Knowledge Management, Vol. 11 No.1 pp.62-71.

[20] Abdi, K. and Aslan, A.S. (2014), "Investigating the impact of knowledge management On organizational innovation: conceptual framework", International Research Journal of Applied and Basic Sciences, Vol. 8 No. 6 , pp. 686-691.

[21] Cross, R., Parker, A., Prusak, L. and Borgatti. S. (2001), "Knowing what we know: Supporting knowledge creation and sharing in social networks" ,Organizational Dynamics, Vol.3 No. 2 pp.100-120. [22] Jones, M. (2001), “Collaborative knowledge management, social networks, and organizational learning", In Proceeding of HCI International: Ninth International Conference on Human-Computer Interaction.

[23] Von Huelsen, P. (2008), "Redes sociais na internet: as comunidades e os blogs como oportunidades para a publicidadee o marketing". São Paulo. Dissertação (Mestrado) Puc.

[24] Grützmann, A., Felício Macedo, F. M. and Zambalde, A. L. ( 2013), "Knowledge Management and Innovation: The Role of Virtual Social Networks in Innovative Consumer Behavior", Journal of technology management \& innovation, Vol. 8 No.1 pp.73-73.

[25] Anderson, S. and Mohan, K. (2011), "Social networking in knowledge management", IT Professional, Vol.13 No. 4 pp.24-28.

[26] Lee, H.S., Lee, S .H. and Han, J,T. ( 2013),“ Social Networks and Knowledge Management", International Journal of Digital Content Technology and its Applications (JDCTA), Vol. 7 No. 12.

[27] Lieshout, M.V., Grossi, L., Spinelli, G. et al. (2007), "RFID technologies: Emerging issues, challenges and policy options. European commission".

[28] Tajima, M. (2007), "Strategic value of RFID in supply chain management". Journal of Purchasing and Supply Management, Vol.13 pp. 261-273.

[29] Sundaram, D., Zhou, W., Piramuthu, S. and Pienaar, S. (2010), "Knowledge-based RFID enabled Web Service architecture for supply chain management", Expert Systems with Applications Vol. 37 pp.7937-7946.
[30] Shaikh, A., Al-Maymouni, R., Al-Hamed, L. and Dardas, A. (2014), "The Role of RFID in Supply Chain Management Macro Processes", International Journal of Innovation, Management and Technology Vol.5 No.5 pp.388-393.

[31] Chao, L., Zhang, Y. and Xing, C. (2012), "The Semantic Web-Based Collaborative Knowledge Management", In New Research on Knowledge Management Technology, Edited by Huei-Tse Hou, Publisher: InTech

[32] Ahsan, K., Shah, H. and Kingston, P. (2009), "Context Based Knowledge Management in Healthcare", An EA Approach, AMCIS Available at AIS library.

[33] Ahsan, K., Shah, H. and Kingston, P. (2010b), "RFID Applications: An Introductory and Exploratory Study" IJCSI International Journal of Computer Science Issues, Vol. 7, Issue.1, No. 3 pp.1-7.

[34] El Ghazali, Y., Lefebvre, É.and Lefebvre, L. A. (2012), "The potential of RFID as an enabler of knowledge management and collaboration for the procurement cycle in the construction industry" Journal of Technology Management \& Innovation, Vol. 7 No.4 pp. 81-102.

[35] Sultan, N. (2013), "Knowledge Management in the Age of Cloud Computing and Web 2.0: Experiencing the Power of Disruptive Innovations", IEEE Engineering Management Review, Vol. 41 No. 4 pp.98-108.

[36] Abdullah, R., Eri, Z.D. and Talib, A.M. (2011), "A model of knowledge management system for facilitating knowledge as a service (KaaS) in cloud computing environment", International Conference on Research and Innovation in Information Systems (ICRIIS), Vol. 23 No.24, pp. 1-4.

[37] Lin, J. and Yang, S.J. (J2013), “An Architecture and Application of Cloud-Based Customer Knowledge Management Information Systems". International Symposium on Biometrics and Security Technologies (ISBAST), Vol. 2 No.5 pp.267-272.

[38] Bimol, S., Saikia, M. and Devi, L.P. (2014), "Achieving knowledge management through Cloud Computing: A case in higher education", International Conference on Computing for Sustainable Global Development (INDIACom), Vol.5, No.7 pp.222-227. 